\title{
The Impact of Change Management on the Efficiency of Organizations: An Applied Study on the DAL Dairy Factory - Sudan 2019 - 2020
}

\author{
Malak S. Hussain ${ }^{1}$ \\ ${ }^{1}$ College of Business, University of Jeddah, Saudi Arabia \\ Correspondence: College of Business, University of Jeddah, Saudi Arabia.
}

Received: May 30, 2021

doi:10.5430/rwe.v12n4p1
Accepted: June 29, 2021

Online Published: July 19, 2021

URL: https://doi.org/10.5430/rwe.v12n4p1

\begin{abstract}
Objectives: This study aims to know the effect of change in culture and technology on efficiency in Dairy Factory Sudan, 2019-2020 and to know the views of managers on the impact of change management on efficiency, to identify the positive aspects that help in improving this efficiency as well as to identify the negatives Which limit the company's efficiency in this field, by answering the following research questions: - Is there an impact of changing culture and technology on increasing the efficiency of institutions? To answer these questions on which the problem is centered around, the following scientific hypotheses were put forward: - There is a statistically significant relationship between changing the organization's culture and increasing the efficiency of organizations, as well as the existence of a statistically significant relationship between changing technology in the organization and increasing the efficiency of organizations. Methods: The descriptive and analytical approach was used to describe the phenomenon under study, and the questionnaire was used to collect various data. The questionnaire was distributed to the sample members who numbered (55) employees to conduct the statistical analysis for this study, through the program used for the statistical analysis of social sciences, the hypotheses were tested by Median and chi-square. Finding: inflating the culture of the departments and divisions of the company, the stagnation and inflexibility of the society's culture, and the inadequacy of that culture to the requirements of work within the community, which led to an overlap in the powers and responsibilities? The most important recommendations: The necessity of changing the organizational structure to comply with the requirements of work, after carefully studying the internal and external environment, and for the change to take place based on the recommendations of specialists in administrative sciences. So that it is not random and does not lead to an inflation of the organizational structure without success. Value: The importance of the study stems from the fact that it addresses an important topic in business administration, which is managing change in organizations, which is the only way for these organizations to develop and continue to exist. It also studies the reality of change management in the DAL Dairy Factory - Sudan.
\end{abstract}

Keywords: management, change, efficiency, organizations

\section{Introduction}

The world around us is constantly changing, and institutions in turn change to ensure their survival and continuity, and change is a permanent feature in the life of organizations in response to achieving the goal of growth, development, competitiveness and responding to renewed customer requirements or as a result of applying a new management philosophy such as Total Quality Management. This is done by seeking to bring about any structural or organizational changes, so that organizations become more flexible in responding to the increasing demands of customers through lower prices or the duration of the exploitation cycle, the abundance of innovations, and the development of new methods of management such as total quality management or the restructuring associated with re-engineering processes Or the acquisition of information and communication technology.

\subsection{The Management of Change}

It is the process of moving from an already existing situation to a targeted one to achieve specific goals within a clear shared vision between the leadership and the workers through which changes are made in a specific system. (Borges, Renata Seamus Guimarães II 2009).

\subsection{Change Management Objectives}

The conversion procedure has two main objectives (Halkos, G. \& Bousinakis, D., 2012). 
- The transition from the current situation to the current development and the shift to the new situation, and depends on the institution to define its goals of renewal.

- Determine the path or direction of change of what this concept carries, the direction of the future, or the window of darkness that it will enter. Directing change towards competition for the development of the organization for its products towards excellence, or an increase in creativity.

\subsection{Justifications for Change}

The need for change is due to many different institutions in the environmental world, which forced them to shift their thinking from the local to the world, which appears to affect several different institutions in several regions in the same market.

To change and recover from long-term risks in the following:

\subsection{External Forces Catalyzing Change}

_ Customer requests.

_ Rapid change in technology for its users.

_ Political and legal changes.

\subsection{Internal Forces Driving Change}

_ Change in machines, products, and production lines.

_ Change in employment structures, jobs, and lab our relations.

\subsection{Methods of Change}

The process of determining the method adopted by the organization in the process of change is important for the success of the change process and the methods of change can be divided into three main methods, namely.

Gradual change: This method of change is adopted to improve productivity, reduce expenditures, or developing employees. This method is characterized by being within a fixed time rate and in a slow manner, and a large or small number of individuals may participate in it.

Drastic change: Large and successful organizations resort to radical change to achieve more profits or to survive and compete strongly. This method is characterized by being surprising and causing a comprehensive reversal in the organization's strategy, especially when entering new markets.

Mixing the two styles: Managers resort to mixing the two styles when negative reactions are expected towards a radical and rapid change in the organization, then graduated programs are started and at the same time or after a specific period, work is done to change the ways of thinking of workers depending on the change that has occurred In circumstances, demands and priorities.

Change Strategies: The occurrence of the change process is related to planning for it according to a strategy implemented by those concerned with change based on discussion and dialogue with the parties demanding it to attract them to the implementation process.

The most prominent of these strategies:

Leadership Excellence Strategy:

It is used in the normal situations of the institution where the leader initiates the idea of change for the sake of a goal resulting from his ambitions or related to the future of the institution according to his expectations.

Strength and Repelling Strategy:

It is based on the use of power and enticement methods to bring about change, whereby the initiator of change uses his influence and power to compel individuals to implement under the threat of punishment or exploit their aspirations and weaknesses to meet their desires by motivating them to implement the task.

Persuasion strategy:

This strategy is based on the use of rationality and logic to convince individuals of the image of change to provide all information indicating the rejection of the current reality and to clarify the goal of the change process and its benefits to the institution and individuals.

Force-sharing strategy: 
It is based on the participation of the institution's members for higher management in identifying possible goals and alternatives to achieve them by the resources and capabilities available to the organization, based on which the problems and difficulties that require changing measures are discovered.

Classifications of change:

There are several types of change, depending on the criteria used in the classification: comprehensiveness, the subject matter of change, speed, planning.

Comprehensive and partial change:

The comprehensive change affects the institution in all its dimensions so that it extends to the strategic directions of the institution with a different effect on all stakeholders. As for the partial change, it is limited to a single sector or field, such as changing machines or work methods, but it can cause some kind of imbalance within the organization as it is a total system. Affects the other, which reduces the effectiveness of change, for example, a change in the method of production calls for changing machines and training personnel.

Physical and moral change:

According to the subject of change, we distinguish between physical change, which includes the structure of the organization or the technology used, and moral change, which includes the psychological and social behavior of individuals.

Rapid change and gradual change:

As for the speed, we distinguish between rapid and slow change. The first is related to the nature of the conditions in which the organization is going through. The second, although it is slow, is more established and effective than the previous one.

Planned and unplanned change:

The plan can be defined as being designed in advance and implemented in an organized and thoughtful way to solve problems or bridge the gaps that may appear between the actual and expected performance of the institution or investment opportunities that have been overlooked.

As for unplanned change, it occurs suddenly and quickly as a result of disputes between individuals and division of labor, as it is implemented directly without taking into account the results.

Stages of change:

Change takes place in several stages as follows:

Determine the internal forces that refer to them.

Recognize the need for change.

Diagnosing, identifying the problem, and treating it with change.

Development of alternatives to change.

- Overcoming resistance to change.

- Implementing the change and following it up from the time difference.

- To bring about change, and to issue publication and information guide.

The concept of organizational culture:

There are many definitions of the concept of organizational culture to include all the basic values it adopts the institution and the philosophy that governs its policy towards employees, customers, and ways to accomplish tasks, and the assumptions and beliefs around which members of the organization rally.

Among the definitions of organizational culture is that it is: "the set of ideologies, philosophies, and values. The beliefs, assumptions, common attitudes, and expectation patterns that characterize individuals in organizing what.

Edgard Schein defines it as the total of individuals 'basic universal, through learning and experiencing the problems that were previously encountered, to achieve external acclimatization, and internal integration, so that everyone works satisfactorily. (Sofat, Kanika, Kiran, Ravi \& Kaushik, Sanjay. 2015)According to Schein, the organizational culture responds to two types of problems to ensure

Enterprise continuity: 
- The organization's response to environmental requirements and thus the continuity of the organization.

- Establishing and maintaining effective work capacities among the members of the organization.

Thus, the organizational culture allows for confronting uncertainty, environmental complexity, and response effective integration of individuals.

Cultures Department:

The strength of institutions is now measured by the degree of influence on individuals to change their habits and behavior, and the management of cultures means the ability to change the culture to adapt to environmental changes because management has shifted from planning, organizing, directing, and controlling the change of culture as well. However, cultural change takes a long time and faces resistance Violent, especially if she is firm. (Jan Brelman, 2013).

The factors that help to change the prevailing culture are the following:

The occurrence of crises or the feeling of their occurrence is a catalyst for change as a way to exit from them or avoid their occurrence.

- A change in leadership calls for dispensing with prevailing values and imposing new ones.

- The size of the organization, in small projects, change is easier than large because it is easy to communicate within the organization to clarify the reasons for the change.

The role of information technology in bringing about change:

Information and communication technology is defined as "the collection of devices."

Software means of communication, database management, and information processing technology used in computer-specific information systems. (Massad, Amin 2019).

(Information and Communication Technology (Tic) affects individual behavior and group behavior in institutions and societies to varying degrees, as all individual and commercial transactions are carried out via the Internet through electronic commerce and financial transactions electronically such as electronic payment. However, there is a lack of experience for these transactions. In addition to the costs of establishing information systems, the expansion of Information and Communication Technology (Tic) applications will result in many changes in the organizations 'behavior to shift towards the information society and then the knowledge society, as knowledge growth, whether fast or slow, is a major source of change. (Alhasimy, 2017.)

As for communications, the modernizing organization adopts the persuasive communication strategy, which is

It is characterized by the following characteristics:

The contact person or message source must be professional, honest, liked by the audience, and in a position to influence others.

The message should have one meaning, that is, clear, summarized, and arranged ideas.

The future audience must be persuaded.

Information and communication technology has contributed to the development of practical applications within organizations through Communication, networking, and developing business relations between the customer and the supplier, as it promoted the transition from manual information processing to automated processing that allows reducing exchange costs. (Gruman, J.A, \& Saks, A.M 2011), as it shows its importance in motivating institutions to respond quickly to changing market positions to continue to grow.

As for its importance in bringing about change, it is due to the following points: (Mandal, Santunu 2015):

- The increasing influence of knowledge and information in industrial societies and the increasing influence of workers in them.

Developing and developing communication networks and dealing with them accurately, which led to the emergence of new information systems based on the use of computers and advanced communication networks.

- Changes that occur in the demand for information and its working methods so that it is seen as the role of information and communication technology in the country, as it is considered a strategic resource, and the effect of the change is as follows: (Tenofiri, H. 2011).

About the change: 
All social, technological, economic, political, and cultural changes surrounding the organization have an impact on human resource management, which requires the organization's management to evaluate this effect on human resource management methods, as it is not only concerned with managing organizational change but rather anticipating its occurrence, searching for opportunities and proposing appropriate solutions. In the strategic framework, the main role of human resources is: (Vosloban, R. I. (2012).

The success of the change process through the active participation of individuals who can effectively manage and lead the change process.

Proficiency and willingness to learn and join the group to work in a team spirit with the ability to self-manage.

The organizational effects of change can affect the change of human resource management by changing the job structure, control systems, and compensation, and technological changes can lead to the abandonment of some jobs and thus the replacement of the machine in the place of the human, which creates some human mechanical interference in the organization.

The most important philosophy affecting human resource management is total quality management. Total quality management requires changes in the organizational culture through changing the behavior of individuals and the ways of performing roles within the organization.

Barriers and problems associated with change:

The usual and familiar obstacles facing the change process mainly include the period because the results pressures in the short term and the insufficient time to bring about the process coincide and show a single risk associated with the change. (Muia, C. 2015).

Factors for success of change in organizations:

It depends on a bunch of factors:

- The appropriate climate to accept change and resist change.

- Senior management support for change efforts.

- Involving workers in change.

- The right time for a change.

\section{Efficiency}

It is not possible to talk about an evolving and continuous organization without a precise definition of the degree of effectiveness of the foundations on which it was built and the extent of its efficiency and ability to achieve the set goals. Where the success of business organizations is determined based on their ability to compete and ensure their existence and continuity, and this can only be achieved through their possession of efficiency and effectiveness, in addition to adherence to high professional ethics, which enhances their competitive position, so that it is difficult to emulate them by competing companies. (Kansal, KK, \& Singh, A. 2016).

Definition of competency:

They represent an evolutionary mixture of experiences, values, and information. And experiences, which in turn form a framework for evaluating and integrating new experiences and information. Therefore, know-how is the reference basis for the formation of knowledge, and the latter is an essential component of competence. (Tinofire, $\mathrm{H}$. 2011).

From a strategic point of view, competencies can be defined as "the sum of practical knowledge that guarantees a competitive advantage in the market. The basic competencies enhance the competitive position of the institution, and therefore the facility in which the competencies are available means that it has a competitive advantage that is one of its strengths.

Efficiency can be defined according to the angle at which it is viewed. Efficiency from the workers' point of view:

"It is the ability that the individual shows in putting his knowledge into practice."

Competence is also defined as "the capabilities to accomplish a set of specific, clear and measurable tasks within the framework of the activity" (Tibbs, Hardin (2011).

It can also be defined as "being rational in using the available resources in a manner that achieves the highest profit by satisfying the needs and desires of working individuals and raising their morale to enhance their desire and drive to work." (Idris, 2012). 
Competence from a management point of view:

It is the system that can reduce the costs of the resources necessary to achieve the specified and desired goals without sacrificing the outputs of the system, meaning that it is the ability to do things correctly.

Inputs used.

Competency management is defined as designing (developing), implementing, and following up harmonized work plans to reduce the differences between needs and the resources of the institution.

Administrative competence is defined as the efficient completion of administrative tasks. A good administration has a good level of general experience in the areas of planning, organizing, directing, and controlling. (Idris, 2012).

Efficiency for owners:

The criterion of rationality in the use of the available material, financial, human, and informational resources, as the organization aiming at growth and development, must ensure the possibility of the continuation of these flows to operate effectively and continuously. The owners of the organization must rely on the rational approach to achieve improvement in the use of available resources, and try to reconcile the planned objectives with the available resources. The exaggeration of attainment of goals, combined with insufficient resources available, makes the owners of the organization suffer from serious failures in the entirety of their activities.

Productivity is defined as:

"The ratio of output / to inputs." (Paracha, M., Qamar, A., Ul-Hassan, I. and Waqas, H. 2012).

Talking about competency as a modern term makes us clash with several terms and concepts that overlap with it in one way or another, as is the case with skill, aptitude, ability, goal, behavior, and achievement ... Hence, we will briefly touch upon it, so that we can define the concept of competence more clearly and distinctly from the neighboring concepts.

Competence is a general concept that includes the ability to use skills and knowledge in worthy positions within a professional field, so it includes organization, planning, innovation, and the ability to adapt to new activities. With these concepts, the acquisition of competencies is a greater challenge than the acquisition of skills and knowledge only.

Lewis Dino's definition of aptitude: Aptitude is a set of social and emotional behaviors, as well as psych sensory-kinesthetic skills that allow to effectively exercise a role, function, or activity. "

The concept of competency denotes the scientific skills that generate value. The French Professional Group defines competence by saying: "Professional competence is a combination of knowledge, skills, experience, and behaviors that are practiced in a specific framework, and it is observed through fieldwork, which gives it the quality of acceptance. And then it is up to the institution to define, evaluate and accept it and its development.

The concept of the organization's efficiency represents the criterion of rationality in the use of human, financial, and material resources and available information, as the organization aiming for growth and development must ensure the possibility of the continuation of human, material, financial and informational flow to operate effectively and continuously.

Some researchers have indicated that the efficiency of the organization is viewed, often from the angle of providing benefits capable of creating a balance in its performance, and this applies to the necessity of adopting the satisfaction of working individuals as one of the indicators expressing the efficiency of performance, especially as the achievement of benefits capable of raising the morale for working individuals, it enhances their continuous contributions to achieving goals with higher degrees of performance efficiency.

In light of this, the concept of performance efficiency depends on the degree of rationality in using the available resources in a manner that achieves the highest returns from them, as well as satisfying the needs and desires of working individuals and raising their morale to enhance their desire and drive to work.( Ishaq, H., Iqbal, M., Zaheer, A. 2009).

Therefore, effectiveness and efficiency are: Performing the right actions in a correct manner and effectiveness is related to leadership, and efficiency is related to management, so effectiveness is achieved when there is a clear vision, specific goals, strategies, principles, values, development, development and other characteristics of leadership, and efficiency is achieved when there is planning, organization, and management of time. And monitoring and follow-up, and when there is effectiveness and there is no competence, the visions and goals do not find someone to 
achieve them properly, and in the absence of effective and presence of competence, the work is completed, but without clarity of objectives.

Types of competencies in the organization:

Individual and collective competencies: Whatever the level of individuals in the organizational structure, the positions they occupy require a specific competency to perform their tasks in a manner that achieves the objectives of the institution. The following are the competencies that should be available in individuals:

- Perseverance and ability to work and adapt to changing and uncertain circumstances.

- The ability to quickly learn and master technological techniques.

- Recruitment of talents, positive interaction with subordinates.

The institution can also obtain individual competence by adopting local standards and foundations in the recruitment process, in addition to the training process that it grants to them in line with the jobs they occupy.

While we consider collective competencies as one of the areas of growing concern for institutions, they arise through the synergy and cooperation of individual competencies, and this is done through a process of communication between them, exchange of information, cooperation, and conflict resolution.

Strategic competencies: The competencies and capabilities of the employees must be identified and compared with those required to achieve the strategic objectives of the institution.

The strategic competencies of the institution are not related only to human resources because the competence of the individual is formed through the sum of the individual qualities "knowledge, skill, behavior," while competencies such as the ability to work effectively are not related to one individual, but are based on cooperation mechanisms within the establishment of mutual influence relations.

In other words, strategic competence comes from how integration is created between individual's competencies and specific coordination mechanisms.

Strategic competencies can be developed from three types of resources:

- Material resources (equipment, technology, buildings, etc.).

- Human resources (capabilities, skills, knowledge, etc.).

- Organizational resources (structuring, oversight, etc.).

Organizational competencies: the organizational competencies of the institution are related to the extent of the response to the changes that occur at the level of its environment, and the shifts in the competitive environment and the degree of its complexity and instability impose on economic institutions high flexibility in managing their human resources to give them the freedom to innovate and develop their individual or collective competencies because institutions that are characterized by flexibility They are organizations that are often efficient in allocating their material and human resources.

Efficiency measurement indicators:

To measure efficiency, there are many indicators and standards used in this regard, including:

Direct standards indicators:

These standards include measuring the organization's operations by comparing the outputs "goods and services" with the inputs "resources used" during a specific period and they include the following:

- Macro measures of efficiency such as (net profit as a measure of total assets or equity).

- Partial measures of efficiency, such as (sales achieved, a measure of the number of employees in the sales department).

- Qualitative measures of efficiency such as (raising the level of product quality using the same resources).

Such indicators may not provide accurate measures, especially in some service activities where it is not possible to use such measures.

Indirect criteria indicators:

Direct standards suffer from deficiencies in measuring competency in some organizations for the following reasons: 
- The inaccuracy of the data related to the inputs and outputs compared to the requirements of achieving the required measurement methods for efficiency.

- The inaccuracy of the comparisons which are the focus of measuring competence, as well as the difficulty of conducting them between the different units and departments of the organization.

Therefore, indirect measurements are considered in some areas a better way to measure efficiency, by measuring willingness to work, and identifying degrees of employee satisfaction and morale, in addition to studying and analyzing the possibility of rational investment of human, material, and financial resources and available information. (Hammoud, Khudair 2010).

It is clear from the above that high efficiency means the optimal use of the organization's resources "inputs with maximizing output." Goods and services Efficiency is measured by the ratio between outputs and inputs.

Therefore, efficiency is generally measured by the ratio of the system's production (output) to resources (input), used to achieve these outputs or outputs.

Proceeding from this, the efficiency can be increased through any of the following alternatives:

Increase the amount of output while the amount of inputs remains constant.

- Increasing the number of outputs by a higher percentage than the increase in the number of inputs.

- The quantity of inputs decreases while the amount of output remains constant.

- The decrease in the number of inputs by a higher percentage than the decrease in the amount of output.

\section{Field Study Procedures}

Founded in 1996, to manufacture dairy and dairy products, in Khartoum - Sudan.

Study tool: The researcher relied on the questionnaire as the main tool to collect field study information, and the answer is done according to the Likert scale, which includes five levels (strongly agree, agree, neutral, disagree, strongly disagree.).

Instrument stability: To ensure the stability of the instrument, it was applied to a sample of ten individuals from the study sample, then it was applied again with an interval of approximately two weeks, and the stability of internal consistency was confirmed using the Cronbach alpha coefficient, whose increase indicates increased data reliability.

\section{Discussion}

Table 1 . The stability parameter for the study tool

\begin{tabular}{ll}
\hline Paragraph & Cranach's Laboratories \\
\hline First & 0.856 \\
\hline the second & 0.849 \\
\hline The third & 0.907 \\
\hline
\end{tabular}

These are all high values suitable for study purposes.

Study sample: A comprehensive survey was conducted on the company's employees, who numbered (55) of all the employees of the company. The study questionnaire was distributed to all the sample members, and (5) questionnaires were retrieved from them.

Analysis and testing of hypotheses:

\subsection{Basic Data}

The first question: Is the company's culture changed according to the goals? 
Table 2. The frequency distribution of the responses of the study individuals to the first question

\begin{tabular}{lll}
\hline data & Repetition & The ratio \\
\hline I agree. & 10 & $20 \%$ \\
\hline I agree. & 30 & $60 \%$ \\
\hline Neutral. & 5 & $10 \%$ \\
\hline I do not agree. & 5 & $10 \%$ \\
\hline Strongly Disagree. & 0 & $0 \%$ \\
\hline Total & 50 & $100 \%$ \\
\hline
\end{tabular}

Source: Prepared by the researcher, from the practical study, 2020.

It is evident from the table that the highest percentage of $60 \%$ of the study sample agree that the company's culture will be changed according to its general goals, while $20 \%$ strongly agree with that, $10 \%$ are neutral, and $10 \%$ disagree.

We conclude from the previous table that the majority of the study sample agrees that a change A Company culture by its general objectives.

The second question: Is the company's culture modified in line with the society's culture?

Table 3. The frequency distribution of the responses of the study individuals to the second question

\begin{tabular}{lll}
\hline data & Repetition & The ratio \\
\hline I agree. & 35 & $70 \%$ \\
\hline I agree. & 10 & $20 \%$ \\
\hline Neutral. & 5 & $10 \%$ \\
\hline I do not agree. & 0 & $0 \%$ \\
\hline Strongly Disagree. & 0 & $0 \%$ \\
\hline Total & 50 & $100 \%$
\end{tabular}

Source: Prepared by the researcher, from the practical study, 2020.

It is evident from the table that the highest percentage of $70 \%$ of the study sample strongly agree that the company's culture should be modified in line with the culture of the society, while $20 \%$ agree to that, and $10 \%$ are neutral.

We conclude from the previous table that the majority of the study sample strongly agrees that the company's culture is modified in line with the society's culture.

The third question: Does the company seek to change events and ways of dealing with them?

Table 4. The frequency distribution of the responses of the study individuals to the third question

\begin{tabular}{lll}
\hline data & Repetition & The ratio \\
\hline I agree. & 14 & $28 \%$ \\
\hline I agree. & 26 & $52 \%$ \\
\hline Neutral. & 10 & $20 \%$ \\
\hline I do not agree. & 0 & $0 \%$ \\
\hline Strongly Disagree. & 0 & $0 \%$ \\
\hline Total & 50 & $100 \%$ \\
\hline
\end{tabular}

Source: Prepared by the researcher, from the practical study, 2020. 
It is evident from the table that the highest percentage of $52 \%$ of the study sample agree that the company seeks to change events and ways of dealing with them, while $28 \%$ strongly agree and $20 \%$ are neutral.

We conclude from the previous table that the majority of the study sample agrees that the company seeks to change events and ways of dealing with them.

The fourth question: Does the company culture consistently consider the customer's interest and change accordingly?

Table 5. The frequency distribution of the responses of the study individuals to the fourth question

\begin{tabular}{lll}
\hline data & Repetition & The ratio \\
\hline I agree. & 32 & $64 \%$ \\
\hline I agree. & 8 & $16 \%$ \\
\hline Neutral. & 4 & $8 \%$ \\
\hline I do not agree. & 4 & $8 \%$ \\
\hline Strongly Disagree. & 2 & $4 \%$ \\
\hline Total & 50 & $100 \%$ \\
\hline
\end{tabular}

Source: Prepared by the researcher, from the practical study, 2020.

It is evident from the table that the highest percentage of $32 \%$ of the study sample strongly agree that the company's culture takes into account the interest of the customer constantly and is changed accordingly, while $8 \%$ agree on that, $4 \%$ are neutral, and $4 \%$ of them do not agree with that, and $2 \%$ do not they strongly agree.

We conclude from this that the majority of the study sample strongly agrees that the company's culture takes into account the interest of the client constantly and is changed accordingly.

The fifth question: The Company seeks to change the technological devices used and develop them to keep pace with the changes?

Table 6. The frequency distribution of the responses of the study individuals to the fifth question

\begin{tabular}{lll}
\hline data & Repetition & The ratio \\
\hline I agree. & 10 & $20 \%$ \\
\hline I agree. & 29 & $58 \%$ \\
\hline Neutral. & 4 & $8 \%$ \\
\hline I do not agree. & 5 & $10 \%$ \\
\hline Strongly Disagree. & 2 & $4 \%$ \\
\hline Total & 50 & $100 \%$
\end{tabular}

Source: Prepared by the researcher, from the practical study, 2020.

It is evident from the table that the highest percentage of $58 \%$ of the study sample agree that the company seeks to change the technological devices used and is working on developing them to keep pace with the changes, while $20 \%$ strongly agree with that, $10 \%$ disagree with that, $8 \%$ are neutral and $4 \%$ Who strongly disagree.

We conclude from the previous table that the majority of the study sample agrees that the company seeks to change the technological devices used and develop them to cope with the changes.

The sixth question: Is the company working to absorb the progress of technological means of communication? 
Table 7. The frequency distribution of the responses of the study individuals to the sixth question

\begin{tabular}{lll}
\hline Data & Repetition & The ratio \\
\hline I agree. & 8 & $16 \%$ \\
\hline I agree. & 31 & $62 \%$ \\
\hline Neutral. & 5 & $10 \%$ \\
\hline I do not agree. & 2 & $4 \%$ \\
\hline Strongly Disagree. & 4 & $8 \%$ \\
\hline Total & 50 & $100 \%$ \\
\hline
\end{tabular}

Source: Prepared by the researcher, from the practical study, 2020.

It is evident from the table that the highest percentage of $62 \%$ of the study sample agree that the company is working to absorb progress through technological means of communication, while $16 \%$ strongly agree with that, and $10 \%$ are neutral, $8 \%$ strongly disagree, $4 \%$ Do not agree.

We conclude from the previous table that the majority of the study sample agrees that the company is working to absorb progress using technological communication.

The seventh question: Does the company provide material and technological facilities to the workers?

Table 8 . The frequency distribution of the responses of the study individuals to the seventh question

\begin{tabular}{lll}
\hline Data & Repetition & The ratio \\
\hline I agree. & 10 & $20 \%$ \\
\hline I agree. & 23 & $46 \%$ \\
\hline Neutral. & 10 & $20 \%$ \\
\hline I do not agree. & 5 & $10 \%$ \\
\hline Strongly Disagree. & 2 & $4 \%$ \\
\hline Total & 50 & $100 \%$ \\
\hline
\end{tabular}

Source: Prepared by the researcher, from the practical study, 2020.

It is evident from the table that the highest percentage of $46 \%$ of the study sample agree that the company provides material and technological facilities to the employees, while $20 \%$ strongly agree to that and are neutral, $10 \%$ disagree and $2 \%$ strongly disagree.

We conclude from the previous table that the majority of the study sample agrees that the company provides material and technological facilities to the workers.

The eighth question: The Company works to change and update the technological programs used?

Table 9. The frequency distribution of the responses of the study individuals to the eighth question

\begin{tabular}{lll}
\hline data & Repetition & The ratio \\
\hline I agree. & 30 & $60 \%$ \\
\hline I agree. & 12 & $24 \%$ \\
\hline Neutral. & 5 & $10 \%$ \\
\hline I do not agree. & 2 & $4 \%$ \\
\hline Strongly Disagree. & 1 & $2 \%$ \\
\hline Total & 50 & $100 \%$ \\
\hline
\end{tabular}

Source: Prepared by the researcher, from the practical study, 2020. 
It is evident from the table that the highest percentage of $60 \%$ of the study sample strongly agree that the company is working to change and update the technological programs used, while $24 \%$ agree to that, $10 \%$ are neutral, $4 \%$ disagree while $2 \%$ strongly disagree with that.

We conclude from the previous table that the majority of the study sample strongly agree that the company is working to change and update the technological programs used.

\subsection{Hypothesis Testing}

Hypothesis: There is a statistically significant relationship between changing the culture and increasing the efficiency of organizations.

Table 10. The chi-square test results for the significance of the differences for the answers to the hypothesis questions and the results the median for the answers of the study individuals

\begin{tabular}{|c|c|c|c|c|c|c|c|}
\hline Phrase & $\begin{array}{l}\text { Calculated } \\
\text { chi-square } \\
\text { value }\end{array}$ & $\begin{array}{l}\text { Degrees } \\
\text { of } \\
\text { freedom }\end{array}$ & $\begin{array}{l}\text { The } \\
\text { probability } \\
\text { value of the } \\
\text { chi-square } \\
\text { test (sig) }\end{array}$ & Interpretatio & & $\begin{array}{l}\text { The median } \\
\text { value for } \\
\text { the phrase }\end{array}$ & Interpretation \\
\hline $\begin{array}{l}\text { The corporate } \\
\text { culture is } \\
\text { changed } \\
\text { according to } \\
\text { its general } \\
\text { goals }\end{array}$ & 50 & 4 & 0.000 & $\begin{array}{l}\text { There } \\
\text { statistically } \\
\text { significant } \\
\text { differences } \\
\text { between } \\
\text { respondents' } \\
\text { answers to } \\
\text { statement }\end{array}$ & $\begin{array}{l}\text { the } \\
\text { the }\end{array}$ & 2.000 & $\begin{array}{l}\text { Respondents' } \\
\text { answers tend to } \\
\text { be favorable }\end{array}$ \\
\hline $\begin{array}{l}\text { The corporate } \\
\text { culture is } \\
\text { modified in } \\
\text { line with the } \\
\text { culture of the } \\
\text { society }\end{array}$ & 50 & 4 & 0.000 & $\begin{array}{l}\text { There } \\
\text { statistically } \\
\text { significant } \\
\text { differences } \\
\text { between } \\
\text { respondents' } \\
\text { answers to } \\
\text { statement }\end{array}$ & $\begin{array}{l}\text { the } \\
\text { the }\end{array}$ & 2.000 & $\begin{array}{l}\text { Respondents' } \\
\text { answers tend to } \\
\text { be favorable }\end{array}$ \\
\hline $\begin{array}{l}\text { The company } \\
\text { seeks to } \\
\text { change with } \\
\text { events and } \\
\text { ways to deal } \\
\text { with them }\end{array}$ & 40 & 4 & 0.000 & $\begin{array}{l}\text { There } \\
\text { statistically } \\
\text { significant } \\
\text { differences } \\
\text { between } \\
\text { respondents' } \\
\text { answers to } \\
\text { statement }\end{array}$ & $\begin{array}{l}\text { the } \\
\text { the }\end{array}$ & 1.6 & $\begin{array}{l}\text { Respondents' } \\
\text { responses tend } \\
\text { to be highly } \\
\text { favorable }\end{array}$ \\
\hline $\begin{array}{l}\text { The corporate } \\
\text { culture is } \\
\text { based on the } \\
\text { client's interest } \\
\text { constantly and } \\
\text { is changed } \\
\text { accordingly }\end{array}$ & 50 & 4 & 0.000 & $\begin{array}{l}\text { There } \\
\text { statistically } \\
\text { significant } \\
\text { differences } \\
\text { between } \\
\text { respondents' } \\
\text { answers to } \\
\text { statement }\end{array}$ & are & 2.000 & $\begin{array}{l}\text { Respondents' } \\
\text { answers tend to } \\
\text { be favorable }\end{array}$ \\
\hline
\end{tabular}

Source: Reality of the Applied Study 2020. 
The results of Table 10 can be interpreted.

1. We notice that the probability value of the chi-square test for the first statement is equal to 0.000 , which is less than the level of significance, meaning that the result of the chi-square test is significant, indicating that there are significant differences between the respondents' answers to the phrase, to know the direction and slope of the differences, we note that the median value of the expression is equal 2.000. Verified and in favor of the approver.

2. We notice that the probability value of the chi-square test for the second statement is equal to 0.000 and it is less than the level of significance, that is, the result of the chi-square test is significant, which indicates the presence of significant differences between the respondents' answers to the phrase, to know the direction and slope of the differences, we note that the median value of the expression is equal 2.000. Verified and in favor of the approver.

3. Note that the probability of the chi-square test for the third statement is 0.000 which is less than

the level of significance, that is, the result of the chi-square test is significant, indicating that there are significant differences between the respondents' answers to the statement, and to know the direction and tendency of the differences, we note that the median value of the statement is equal to 1.6, meaning that the statement is valid and in favor of those who agree strongly.

4. We notice that the probability value of the chi-square test for the second statement is equal to 0.000 and it is less than the level of significance, that is, the result of the chi-square test is significant, which indicates the presence of significant differences between the respondents' answers to the phrase, to know the direction and slope of the differences, we note that the median value of the expression is equal 2.000. Verified and in favor of the approver.

It also appears that the value of the significance level for all the elements of cultural change in increasing the efficiency of the organizations combined is equal to 0.000 and it is less than 0.05 , and the calculated value of the axes of change in the company's culture according to its general objectives and is greater than the tabular value, which indicates the existence of a statistically significant relationship between The elements of change in the interest of the customer constantly and is changed according to the performance of the employees, and this indicates that the systematic and scientific changes in the culture of society will lead to improved performance.

The second hypothesis: There is a statistically significant relationship between changing technology and increasing the efficiency of organizations.

Table 11. The results of the chi-square test for the significance of the differences for the answers to the second hypothesis questions and the median results for the answers of the study individuals

\begin{tabular}{|c|c|c|c|c|c|c|}
\hline Phrase & $\begin{array}{l}\text { Calculated } \\
\text { chi-square } \\
\text { value }\end{array}$ & $\begin{array}{l}\text { Degrees } \\
\text { of } \\
\text { freedom }\end{array}$ & $\begin{array}{l}\text { The } \\
\text { probability } \\
\text { value of the } \\
\text { chi-square } \\
\text { test (sig) }\end{array}$ & Interpretation & $\begin{array}{l}\text { The median } \\
\text { value for } \\
\text { the phrase }\end{array}$ & Interpretation \\
\hline $\begin{array}{l}\text { The company } \\
\text { seeks to change } \\
\text { the technological } \\
\text { devices used and } \\
\text { develop them to } \\
\text { keep pace the } \\
\text { changes. }\end{array}$ & 60 & 4 & 0.000 & $\begin{array}{l}\text { There are } \\
\text { statistically } \\
\text { significant } \\
\text { differences } \\
\text { between the } \\
\text { respondents' } \\
\text { answers to the } \\
\text { statement }\end{array}$ & 2.4 & $\begin{array}{l}\text { Respondents' } \\
\text { answers tend to } \\
\text { be favorable. }\end{array}$ \\
\hline $\begin{array}{l}\text { The company is } \\
\text { working to absorb } \\
\text { advances in } \\
\text { technological } \\
\text { communication. }\end{array}$ & 60 & 4 & 0.000 & $\begin{array}{l}\text { There are } \\
\text { statistically } \\
\text { significant } \\
\text { differences } \\
\text { between the } \\
\text { respondents' } \\
\text { answers to the } \\
\text { statement. }\end{array}$ & 2.4 & $\begin{array}{l}\text { Respondents' } \\
\text { answers tend to } \\
\text { be favorable. }\end{array}$ \\
\hline
\end{tabular}




\begin{tabular}{|c|c|c|c|c|}
\hline $\begin{array}{l}\text { The company } 60 \\
\text { provides physical } \\
\text { and technological } \\
\text { facilities to the } \\
\text { workers. }\end{array}$ & 4 & 0.000 & $\begin{array}{l}\text { There are } 2.4 \\
\text { statistically } \\
\text { significant } \\
\text { differences } \\
\text { between the } \\
\text { respondents' } \\
\text { answers to the } \\
\text { statement. }\end{array}$ & $\begin{array}{l}\text { Respondents' } \\
\text { answers tend to } \\
\text { be favorable. }\end{array}$ \\
\hline $\begin{array}{l}\text { The company } 60 \\
\text { works to change } \\
\text { and update the } \\
\text { technological } \\
\text { programs used. }\end{array}$ & 4 & 0.000 & $\begin{array}{l}\text { There are } 2.4 \\
\text { statistically } \\
\text { significant } \\
\text { differences } \\
\text { between the } \\
\text { respondents' } \\
\text { answers to the } \\
\text { statement. }\end{array}$ & $\begin{array}{l}\text { Respondents' } \\
\text { responses tend } \\
\text { to be highly } \\
\text { favorable. }\end{array}$ \\
\hline
\end{tabular}

Source: Reality of the Applied Study 2020.

The results of Table 11 can be interpreted:

1. We notice that the probability value of the chi-square test for the first statement is equal to 0.000 and it is less than the level of significance, that is, the result of the chi-square test is significant, which indicates the presence of significant differences between the respondents' answers to the statement. Verified and in favor of the approver.

2. Note that the probability of the chi-square test of the second statement is equal to 0.000 , which is less than

The level of significance, that is, the result of the chi-square test is significant, indicating that there are significant differences between the respondents' answers to the statement. To know the direction and tendency of the differences, we note that the median value of the statement is equal to 4. 2 That is, the statement is valid and in favor of the approver.

3. Note that the probability of the chi-square test for the third statement is 0.000 which is less than

The level of significance, that is, the result of the chi-square test is significant, indicating that there are significant differences between the respondents' answers to the statement. To know the direction and tendency of the differences, we note that the median value of the statement is equal to 4 . 2 That is, the statement is valid and in favor of the approver.

4. We notice that the probability value of the chi-square test for the fourth statement is equal to 0.000 , which is less than the level of significance, that is, the result of the chi-square test is significant, indicating that there are significant differences between the respondents' answers to the statement. 2 That is, the statement is valid and strongly favorable to consent.

It is also found that the value of the significance level of all the elements of technology change in increasing the efficiency of the organizations combined is equal to 0.000 and it is less than 0.05 , and the calculated value of the axes of changing the technological devices used and developing them to keep pace with changes in the performance of workers and it is more than the tabular value, which helps to provide material and technological facilities for workers and provide Modern technological programs and their development in the efficiency of the organization, and this indicates the need for change in technology in proportion to the requirements of work to raise the efficiency of performance in the organization.

\section{Conclusion}

The change in the company's culture was not clear to the teacher, due to the creation of changes in the general objectives that serve the personal interests of a particular group, without examining the changes required by the work to improve the performance of workers and without reviewing the internal and external environment, and not redistributing the powers to conform to the requirements of the work.

The inflation of the company's culture of departments and divisions, the rigidity and inflexibility of the community's culture, and the inadequacy of that culture to the requirements of work within the community led to an overlap in the 
powers and responsibilities.

Unavailability of the elements of change management, due to the lack of study of the internal and external environment, the absence of plans that define areas of change, the lack of a flexible organizational structure, the lack of effective leadership capable of convincing workers to change, the lack of good lines between management and workers, lack of clarity of powers and responsibilities and lack of Making decisions scientifically and systematically.

The absence of the role of the leader who can convince employees of the importance of change, the inability to communicate with workers, as well as the absence of an incentive system for hardworking workers who can present new ideas.

This study contributes to enriching the research on change management and raising the efficiency of enterprises. It provides an opportunity to suggest similar studies on the subject from different sides to learn more about this administration and its importance.

\section{Search Limitations}

The limitations of this paper are the small sample size, the lack of response in the required form, and the lack of sufficient previous studies on the topic.

\section{Recommendations}

Based on the previous results, the research concluded a set of recommendations that may be good suggestions to overcome the negatives, which are as follows:

1. The necessity for the change in the organizational structure to be in line with the requirements of the work, after carefully studying the internal and external environment, and for the change to take place based on the recommendations of specialists in management sciences so that it is not random and does not lead to an inflated organizational structure without success.

2. That the units, departments, and jobs are announced on the organizational structure and that these positions are appointed by setting professional standards that are required to be provided by the incumbent, and after passing a competition to ensure the competence of those appointed.

3. The need to define the authority and responsibility for each functional department so that there is no overlap in the powers, and to reduce the centralization so that it works to delegate the powers to other levels, which leads to the speedy completion of work.

4. The necessity of involving workers in decision-making, and benefiting from the ideas they provide, as they are the most capable of generating new ideas, knowing the problems facing work, and proposing solutions to those problems.

\section{Future Limits and Paths of Research}

The limitation of this study lies in the use of one method of investigation which is change. It would be interesting to extend this study with a quantitative experiment to validate the main finding of this study. If we consider that the latent can be a personal characteristic, such as the use of skills that increase the efficiency and development of work and thus bring about the required change. It is clear if soft skills can be appropriately managed to become particularly critical research issues for the future.

\section{References}

Al-Hashemi, A.-R. (2017). Curriculum and knowledge-economy. Amman: Dar Al-Masirah for Publishing and Distribution.

Borges, R. S. G. E. (2009). Organizational change implementation and the role of human resource practices: a Brazilian case study. Brazilian Business Review, 6(3), 284-295. https://doi.org/10.15728/bbr.2009.6.3.5

Brilman, J. (2013). Les millers parties de management. Paris: Editions D Organizations. Retrieved from http://nrs.harvard.edu/urn-3:HUL.InstRepos:23845399

Gruman, J. A., \& Saks, A. M. (2011). Performance Management and Employee. Human Resource Management Review, 21(2), 123-136. https://doi.org/10.1016/j.hrmr.2010.09.004

Halkos, G., \& Bousinakis, D. (2012). Importance and influence of organizational change on companies and their employees. MPRA Paper No. 36811.

Hardin, T. (2011). Changing cultural values \& the transition to sustainability. UK: University of Oxford. 
Idris, T. A. R. (2012). Efficiency and quality of logistics services. Alexandria: University House. https://doi.org/10.6007/IJARAFMS/v7-i1/2613

Ishaq, H., Iqbal, M., \& Zaheer, A. (2009). Effectiveness of Performance Appraisal: Its Outcomes and Detriments in Pakistani Organizations. European Journal of Social Sciences, 10(3).

Kanika, S., Ravi, K., \& Sanjay, K. (2015). Management of organizational change and its impact on commitment: a study of select Indian IT companies. Global Business \& Management Research, 7(3), 69-86.

Kansal, K. K., \& Singh, A. (2016). Impact of organization change on employee's performance in Maruti Suzuki. International Journal of Research in IT and Management, 6(11), 21-16. Retrieved from http://euroasiapub.org

Khudair, H. (2010). Knowledge organization, Oman: safaa house for publishing and distribution. Retrieved from http://dspace.alazhar.edu.ps/xmlui/handle/123456789/637

Massad, A. (2019). Efficiency in operations management. Knol's website, Knowledge Unit. https://doi.org/10.2175/106143010X12756668802292

Muia, C. (2015). Change Management Challenges Affecting the performance of Employees: A Case Study of Kenya Airports Authority, Nairobi. A Research Project Submitted to the School of Management and leadership In Partial Fulfilment of the Requirement for the Award of the Degree of Executive Masters in Business administration of the Management University of Africa. https://doi.org/10.1007/978-1-349-27315-7.

Paracha, M., Qamar, A., Ul-Hassan, I., \& Waqas, H. (2012). Importance of leadership style (Transformational \& Transformational leadership) on employee performance \& mediating role of job satisfaction: Study of private school (educator) in Pakistan. Global Journal of Management and Business Research, 12(4), 1-39.

Santanu, M. (2015). Supply And demand effects on supply chain flexibility: an empirical exploration. Knowledge and Process Management, 22(3), 206-219. https://doi.org/10.1002/kpm.1475

Tinofirei, H. (2011). The unique factors affecting employee performance in non- profit organizations. The University of South Africa.

Vosloban, R. I. (2012). The influence of the employee's performance on the company's growth-a managerial perspective. Procardia Economics and Finance, 3, 660-665. https://doi.org/10.1016/S2212-5671(12)00211-0

\section{Copyrights}

Copyright for this article is retained by the author(s), with first publication rights granted to the journal.

This is an open-access article distributed under the terms and conditions of the Creative Commons Attribution license (http://creativecommons.org/licenses/by/4.0/). 